\title{
Emerging aspects of assessing lead poisoning in childhood
}

\author{
AL Jones
}

Discipline of Clinical Pharmacology and Clinical Toxicology, School of Medicine and Public Health and Calvary Mater Hospital, University of Newcastle, Callaghan, Australia

Correspondence

Professor AL Jones, School of Medicine and Public Health and Calvary Mater Hospital, University of Newcastle, Callaghan, NSW 2210, Australia.

E-mail:

alison.jones@newcastle.edu.au

Received 10 May 2008

Revised 14 December 2008

Accepted 22 January 2009

\begin{abstract}
This review covers the epidemiology of lead poisoning in children on a global scale. Newer sources of lead poisoning are identified. The methods that are used to assess a population of children exposed to lead are discussed, together with the ways of undertaking an exposure risk assessment; this includes assessing the time course and identifying sources of lead exposure. Human assessment measures for lead toxicity, such as blood lead concentrations, deciduous tooth lead, and use of zinc protoporphyrin estimations are evaluated. The role of isotopic fingerprinting techniques for identifying environmental sources of exposure is discussed. Among emerging data on the cognitive and behavioral effects of lead on children, the review considers the growing evidence of neurocognitive dysfunction with blood lead concentrations even below $10 \mu \mathrm{g} / \mathrm{dl}$. The challenge of assessing and explaining the risk that applies to an individual as opposed to a population is discussed. Intervention strategies to mitigate risk from lead are examined together with the limited role for and limitations of chelation therapy for lead. Lessons learned from managing a population lead-dust exposure event in Esperance, Western Australia in 2007 are discussed throughout the review.
\end{abstract}

\section{Introduction}

Lead exposure remains a major environmental issue around the world, as the poverty of measures to deal effectively with the problem in both developing and developed countries has led to significant ongoing exposure. The annual cost of the health effects of lead exposure in the United States alone was estimated at US\$43.5 billion in 1997-much higher than that associated with any other environmental toxin. ${ }^{1}$ Few doubt that lead exposure has significant health consequences at levels below those considered medically acceptable decades ago, but there is still debate over what levels of lead exposure in the modern world, if any, can be considered of minimal harm.

This review focuses on lead poisoning in children because of the high prevalence of lead in the environment, and because the impact of lead exposure on children's neurocognitive development, in particular, is substantial. ${ }^{1}$ Emerging data suggest a health impact on neurocognitive function at much lower blood concentrations of lead than thought earlier. $^{2-5}$ Children are particularly sensitive and susceptible to lead toxicity and as such are a subpopulation ${ }^{6}$ at which prevention strategies need to be targeted. Childhood lead remains a major public health problem for certain groups of children, specifically African-American children in the USA, ${ }^{1,7}$ children living in areas of low socioeconomic status, ${ }^{8}$ children living in rural mining communities, and children in developing countries such as India and the Philippines. ${ }^{9,10}$ This paper also presents a case study of the assessment of children exposed to lead in Esperance, Western Australia, to illustrate the principles of managing such events from a public health perspective, as well as the scientific rationale for this approach.

\section{Ethical background}

To illustrate the issues of children's lead exposure and management, a case example of environmental exposure in Esperance, Western Australia, is frequently referred to in this review. All human data in this paper were obtained for clinical or public health prevention purposes, and thus a formal research ethics application was not submitted or required to undertake this review. However, the blood sampling conformed to Western Australian Health department guidelines and ethical principles. This paper uses publicly available data on the Esperance lead-contamination incident.

This is an Open Access article distributed under the terms of the Creative Commons Attribution licence which permits unrestricted use, distribution, and OPEN - access reproduction in any medium, provided the original work is properly cited. 


\section{Lessons from managing the lead exposure incident in Esperance}

Esperance is a town on the Southern Coast of Western Australia, $721 \mathrm{~km}$ from Perth, which enjoys a reputation of a 'pristine environment,' with 'snow white beaches,' clear 'aqua blue waters,' and an 'abundance of wildlife.' ${ }^{\prime 1}$ In December 2006, Esperance community members reported that birds were 'actually falling from the sky,' and by the end of March 2007 local government agencies had estimated that the total number of bird deaths in the area was $4500 .{ }^{11}$ The detection of elevated lead concentrations in the liver of these birds prompted an environmental investigation that identified significant lead-dust contamination in the town. The point source was found to be the Port of Esperance, which had begun storing and shipping lead carbonate (ore) in 2005. Dust from the port had contaminated rooves; therefore, drinking water from rainwater tanks was a significant source of lead exposure for the population. This newer source contrasts in duration of exposure with the lead mining and smelters found in areas of Australia such as Broken Hill and Port Pirie. ${ }^{12,13}$ The difference is seen in the magnitude of clinical effects but also in terms of appropriate remediation strategies and health surveillance. Sadly, much disproportionate fear has been invoked in the population of Esperance from stories of lead-smelting areas in Australia.

Concern was expressed by the local population about the potential for lead poisoning among children, and those with blood lead concentrations $\geqslant 5 \mu \mathrm{g} / \mathrm{dl}$ entered a blood test surveillance programme, where testing occurred at threemonth intervals. The aim of such a programme was to evaluate if ongoing exposure and lead accumulation was occurring after environmental remediation had taken place. The level of $5 \mu \mathrm{g} / \mathrm{dl}$ was chosen to give a margin of safety (being significantly lower than the intervention level of $10 \mu \mathrm{g} / \mathrm{dl}$ set by the US Centers for Disease Control and Prevention, CDC, discussed below), and to ensure a sufficient sample size across the town for meaningful data collection. Isotopic lead estimation (described below) was also used, and data collected with this technique revealed that several children had significant blood lead levels associated with exposures from sources other than the primary point source (i.e., the Port).

Active measures were taken to control the population's lead exposure through dust. These measures included advice against drinking water from rainwater tanks (contaminated by dust), wet mopping of dust, cleaning with other methods, and hand washing. As a consequence, average blood lead concentrations in children five years of age or younger fell rapidly at three and six months after these measures were instituted. ${ }^{14}$

The role of the toxicologist in risk communication is important and conventional concepts in risk communication, such as consistency of messaging and explaining relative risks, were applied in Esperance. ${ }^{15-19}$ Risk messages about the absence of serious toxicity risk were communicated while urging the residents not to be complacent.
This message was both simple and wholly reliable. It was important that the toxicologist involved in the response to the Esperance incident had no connection with government agencies. The role was to keep an active communications channel with concerned members of the public and professionals alike, and to problem-solve where communications had slipped. To ensure that the message had reached the entire community, toxicologists and public health physicians personally saw parents, general practitioners, and community leaders such as aboriginal communities, pediatricians, and activist groups. ${ }^{11}$ It was important to be prepared to explain the detailed science and medicine behind decisions to those who sought to understand them. For example, explaining the risks to an individual versus the whole population for lead's effect on IQ, and explaining some of the confounding factors considered in interpreting existing studies.

It was also helpful to give people choice in how they responded to the situation, for example, by offering a variety of intervention strategies (see below) to reduce ongoing exposure. These included hand washing, availability of highefficiency particulate air (HEPA) vacuums, personal house cleaning, and professional house cleaning. ${ }^{11}$

It was important to acknowledge the fear provoked by the event. Key to managing this incident was to understand that the community had chosen to live in Esperance because it was a pristine environment. It was also important to understand concerns about the impact of pollution on that image and the prospects of loss of income from tourism.

\section{Potential sources of lead exposure}

Longstanding and ongoing sources of external exposure to environmental lead include lead-smelter areas, ${ }^{12}$ melted lead batteries, ${ }^{20}$ lead in drinking water, $^{21,22}$ the glazing industry, ${ }^{23}$ and lead paint. ${ }^{22}$ Moreover, exposure can occur in work environments ${ }^{24}$ and through the transfer of lead from mother to fetus, ${ }^{25-27}$ which occurs with a placental transmission ratio of 0.6 . The transfer of lead from mothers to nursing infants through breast milk occurs in much lower amounts by comparison, with the mammary gland being a barrier that effectively maintains a low milk:plasma ratio for lead. ${ }^{25-27}$ Despite a documented wide range of lead concentrations in human milk, there have been no reports of toxicity caused by breast feeding. ${ }^{25}$ For children in non-lead polluting industrial areas, paint provides the most common source of exposure to lead.

In many developed countries, a reduction in the use of leaded petrol over the last decade has diminished lead poisoning; this has led to complacency. ${ }^{7,28}$ The ban of leaded petrol in Australia, in effect since 2002, has resulted in declining blood lead levels - though interestingly, even today some dust from roadsides still contains significant concentrations of lead (Peter Baghurst, personal communication). The most recent Australian National blood lead survey, conducted in 1996 by the Australian Institute of Health and Welfare (AIHW), found a mean blood lead level 
of $5.8 \mu \mathrm{g} / \mathrm{dl}$ in a random sample of children, where $92.7 \%$ of lead levels recorded were below $10 \mu \mathrm{g} / \mathrm{dl}^{29}$ The US National Health and Nutrition Examination Survey (NHANES) of 1976-1980, 1991-1994, and 1999-2002 has documented a steady decline in the number of children aged one to five years in the USA with blood levels $>10 \mu \mathrm{g} / \mathrm{dl}$, from $77.8 \%$ to $4.4 \%$ and to $1.6 \%$, respectively. ${ }^{30}$ The average blood lead level for Swedish children aged 7-11 years whose residence was not near industrial sources of the chemical was $2.1 \mu \mathrm{g} / \mathrm{dl}$ between 1995 and 2001. ${ }^{31}$

However, pockets of ongoing population exposure to lead still occur in developed countries. For example, the Guys and St. Thomas Medical Toxicology Clinic in the UK saw many tens of patients with significant lead poisoning requiring chelation therapy in South London from 1998-2006. Lead paint from Victorian houses remains a source of lead poisoning when it chips and flakes before and during restoration. ${ }^{32}$ This is also a source of exposure in the USA, ${ }^{33}$ where the economically disadvantaged, recent migrants, and children with developmental delays are at a higher risk of lead exposure than the general population. ${ }^{7}$ Mean blood lead concentrations in these higher risk populations have declined over time, but remain elevated in some locations and among some populations. $^{34}$

More recently identified sources of lead exposure for children include industrial environmental sources, such as the shipping of lead in the case of Esperance. Newly identified sources of lead poisoning over the last 10 years also include fishing weights, otherwise known as sinkers, ${ }^{35}$ snooker chalk, ${ }^{36}$ and lead paint found on products including children's toys and barbeques. Increasing globalization has a marked impact on risk as, for example, in the case of lead paint on toys made in China ${ }^{37}$ appearing in shops in the USA and Australia. As a result, there is an increasing need for public health authorities to be vigilant for both domestic and imported lead hazards and to put surveillance systems in place for early identification of such hazards. The most recent US death associated with lead toxicity ${ }^{38}$ was in a child who swallowed metal jewelry. This 'imported risk' may affect certain ethic groups more than others. For example, significant amounts of lead are found as a contaminant or an intentional adulterant in some herbs and ethnic remedies including ayurvedic herbal products, ${ }^{39}$ imported spices, or Hispanic folk remedies such as 'litargirio'. ${ }^{27}$ However, toys made with lead paint are distributed more widely than these remedies.

\section{What effect does lead have on children? General principles}

Lead is neurotoxic. ${ }^{40}$ It interferes with signal transmission at the synapse and interferes with cellular adhesion molecules, causing disruption in cellular migration during critical times of nervous system development. Disruption of subunit expression of the $N$-methyl-D-aspartate receptor (NMDAR) and NMDAR-mediated calcium signaling in glutamatergic synapses is considered the main mechanism of lead-induced deficits in synaptic plasticity, and in learning and memory deficits documented with animal models of lead toxicity. ${ }^{41}$ At fairly substantial levels of exposure, lead inhibits the enzymes ferrochelatase and delta amino levulinic acid dehydratase, ${ }^{42}$ resulting in microcytic hypochromic anemia.

There is no single clinical neurological set of effects that make up a 'signature' injury associated with lead exposure. Deficits have been reported in verbal IQ, performance IQ, academic skills such as reading and maths, visuo-spatial skills, problem solving, fine and motor skills, memory and language skills. ${ }^{7,43-45}$ As methods of measuring both lead exposure and cognitive development become more sensitive, subtle adverse impacts of very low blood lead levels become more quantifiable. One of the greatest challenges facing clinicians dealing with lead issues today is determining what this means for individual patients and populations, and mitigating these risks.

\section{Emerging literature on health effects of blood lead concentrations $>10 \mu \mathrm{g} / \mathrm{dl}$}

Several older meta-analyses of observational epidemiological studies indicate that a child's IQ scores decline $2-3$ points per $10 \mu \mathrm{g} / \mathrm{dl}$ increase in blood lead level ${ }^{12,46}$ between 10 and $30 \mu \mathrm{g} / \mathrm{dl}$. Below $10 \mu \mathrm{g} / \mathrm{dl}$, a pooled analysis using a log-linear model shows that the function that best describes the data predicts a 9.2 point decline in IQ over the range of $<1$ to $30 \mu \mathrm{g} / \mathrm{dl}$; with two thirds of the decline predicted to occur in the range of $<1$ to $9.9 \mu \mathrm{g} / \mathrm{dl}^{2}{ }^{2}$ A plausible explanatory hypothesis for such findings is a lead-sensitive effect that is rapidly saturated at blood levels $<10 \mu \mathrm{g} / \mathrm{dl}^{7}{ }^{7}$ Some longrunning prospective studies suggest that lead-associated neurodevelopmental deficits induced by postnatal exposure resolve over several years. ${ }^{3}$ But other studies, such as those involving the Port Pirie data, ${ }^{2,13}$ do not indicate this. Moreover, brain functional imaging studies show differences between those people with and without past exposure to the metal. ${ }^{47}$ At higher doses, the impacts of lead include damage to the nervous, hemopoeitic, endocrine, ${ }^{48}$ and renal $^{49}$ systems. Data indicate that lead contributes to nephrotoxicity even at blood lead levels below $5 \mu \mathrm{g} / \mathrm{dl}$, especially in susceptible population groups such as those with hypertension, diabetes mellitus, or chronic renal disease. ${ }^{1,10,30,49,50}$

\section{Emerging literature on health effects of blood lead concentrations $<10 \mu \mathrm{g} / \mathrm{dl}$}

Recent studies suggest that there is no concentration threshold for injury from absorbed lead in children, and blood lead levels under $10 \mu \mathrm{g} / \mathrm{dl}$ have been correlated with declining IQ scores. ${ }^{4,51,52}$ Lanphear et al. ${ }^{5}$ found that for every $1 \mu \mathrm{g} / \mathrm{dl}$ increase in lead concentration there was a 0.5 point decrease in average scores of arithmetic and reading for children whose blood lead concentrations were $<5 \mu \mathrm{g} / \mathrm{dl}$. Individual studies associating blood lead levels below $10 \mu \mathrm{g} / \mathrm{dl}$ with adverse cognitive impacts must be interpreted carefully, in light of what is known about timing of exposure 
in relation to child development, outcome measures, methodological limitations, and the importance of controlling for confounding and effect-modifying variables that include socioeconomic status, maternal education, and housing quality. ${ }^{51,52}$

The evidence that has evolved over the past five years on the dose-response relationship below lead levels of $10 \mu \mathrm{g} / \mathrm{dl}$ has clear implications for policy decisions based on it. ${ }^{53}$ In 1991, the US CDC chose $10 \mu \mathrm{g} / \mathrm{dl}$ as an initial screening level of concern for lead in children's blood. Current data on health risks and intervention options do not support generally lowering that level, but federal lead-poisoning prevention efforts in the USA have revised the follow-up testing schedule for infants aged one year or less with blood lead levels of $5 \mu \mathrm{g} / \mathrm{dl}$ or higher, rather than $10 \mu \mathrm{g} / \mathrm{dl}$ or higher. ${ }^{51,52}$ This level was also applied as the cutoff for ongoing surveillance in Esperance as described above. One review suggests lowering the blood lead action level from 10 to $2 \mu \mathrm{g} / \mathrm{dl} .{ }^{54}$ Such a suggestion needs to be put in the context of the laboratory methods' sensitivity to detect lead. ${ }^{55}$ To help in interpreting blood lead levels, clinicians need to understand the laboratory error range for blood lead values, and to select a laboratory that achieves levels within $\pm 2 \mu \mathrm{g} / \mathrm{dl}^{.55}$ The US Agency for Toxic Substances and Disease Registry (ATSDR) has refused to set a minimum risk level because some of the health effects associated with exposure to lead occur at blood levels so low as to indicate that toxicity occurs essentially without a threshold. ${ }^{54}$ Bernard $^{51}$ has suggested that very young children with blood lead levels above the national average should be tested more frequently. The CDC also suggested more frequent testing for some children whose blood lead levels are in the range of $5-9 \mu \mathrm{g} / \mathrm{dl} .{ }^{52}$ Bernard advocates education about the dangers of lead, the use of blood lead surveillance, and the collection of additional data to identify populations at risk. The risk to an individual of a small drop in IQ is minimal, but the population risk of an effect on IQ, or other health outcomes, is great. $^{48}$

\section{Factors that make children most susceptible to lead toxicity}

It is only recently that the concept of considering children as a sensitive subpopulation in health risk terms has gained acceptance in environmental toxicology. Children are more susceptible to the adverse effects of lead than adults for several reasons. Lead exposure around 28 weeks of gestation coincides with a time of critical neurological development, leading potentially to permanent effects even at low levels. ${ }^{56,57}$ As infants and toddlers, their behavior is marked by a high frequency of hand-to-mouth activities, and hence they tend to ingest more dust. ${ }^{7,58}$ The fraction of ingested lead absorbed by young children is higher than that absorbed by adults ${ }^{7,58}$ and the developing nervous system is more susceptible to toxins. ${ }^{7,58,59}$ In addition, some children have an urge to repetitively consume non-food products such as lead paint flakes - this is called pica. ${ }^{7,58}$

\section{Assessing a population that may have been exposed to lead}

When assessing a population that may have been exposed to lead, the following factors need to be taken into consideration:

- Time course and sources of exposure

- Type of lead compound involved and its physical form, for example dust, pellets, paints, dissolved lead in solution

- The age distribution of the children exposed

Children's risk of lead poisoning correlates positively with their ability to walk and their hand-to-mouth behavior. Typically, peak blood lead levels occur by 18-30 months of age and then decline gradually through the rest of toddler and school years. ${ }^{7}$ Children who have persistent pica are at high risk for continued lead exposure well into their schoolaged years; this includes those children with developmental delays. Most young children are exposed by poisoned by the ingestion of lead-containing dust as a result of hand-tomouth behaviors. In a poisoning incident, inquiry into the possible lead contamination of all the environments in which the child spends significant amounts of time needs to be undertaken. What is the age of the house? Have any renovations taken place recently? Are there bite marks on windows or furniture? Other potential sources of lead also need to be considered (Table 1). What source of water does the family use for drinking? The family's dust control and hand-washing behaviors need to be known. A full physical examination with an emphasis on neurological function is required as part of the assessment. Parents may describe irritability, insomnia, aggressiveness, lack of focus and attention, poor appetite, and speech delays. But these features are, of course, also found in non-lead exposed children, ${ }^{7}$ and most children with blood lead levels considered elevated will be asymptomatic, showing no physical signs of poisoning. A developmental evaluation should be considered and appropriate developmental monitoring should be established.

Table 1 A checklist of sources of lead poisoning

\begin{tabular}{|c|c|}
\hline Home & $\begin{array}{l}\text { Occupational sources that can bring } \\
\text { lead dust into the home }\end{array}$ \\
\hline $\begin{array}{l}\text { Toys, crayons, cribs, furniture }{ }^{83,84} \\
\text { Contaminated foods, e.g., flour }^{84,85} \\
\text { Surma (kohl) cosmetics } \\
\text { Ceramic bowls, glazes }^{85} \\
\text { Drinking water from lead pipes } \\
\text { Dust }^{87} \\
\text { Traditional remedies }^{84} \\
\text { Soldered pots, kettles } \\
\text { Paint, plaster, putty } \\
\text { Metallic jewelry } \\
\text { Soil } \\
\text { Snooker chalk }^{89} \\
\text { Lead fishing weights/sinkers }^{85} \\
\text { Renovations }\end{array}$ & $\begin{array}{l}\text { Car repair }^{91} \\
\text { Mining }^{84} \\
\text { Smelting }^{84} \\
\text { Demolition }^{92} \\
\text { Battery manufacture } \\
\text { Construction }^{93} \\
\text { Pipe fitting }^{94,95} \\
\text { Plumbing }^{94,95} \\
\text { Shipbuilding }^{96} \\
\text { Bridge reconstruction }^{97} \\
\text { Glazing, pottery }^{85}\end{array}$ \\
\hline
\end{tabular}




\section{Diagnostic modalities for assessing lead poisoning in children}

The best way to assess the degree of lead poisoning in children is by taking venous blood for lead estimation. Heel or finger prick testing is prone to significant error because of environmental skin contamination. ${ }^{7}$ However, with prior thorough cleaning of the skin, it has been used by many to collect biomonitoring samples. Recently, in undertaking health surveillance after the lead-dust exposure scenario in Esperance, venous blood testing was performed on children under five years of age without the anticipated difficulties of difficult venous access. Retesting was carried out at three monthly intervals in children with lead concentrations $>5 \mu \mathrm{g} / \mathrm{dl}$, and showed significant expected falls (with the estimated elimination half-life of lead from blood being 30 days). ${ }^{60}$ This showed that bioaccumulation from ongoing environmental exposure was not occurring, since a rapid fall in concentration indicates long-term exposure. Roberts et al. ${ }^{60}$ found that the average time for blood lead to decline was linearly related to the peak concentration of blood lead, but the time for $50 \%$ of the blood lead to decline to $<10 \mu \mathrm{g} / \mathrm{dl}$ was not linear and varied with peak lead levels. Venous blood lead estimation is a short-term measure of lead exposure (half-life of 30 days) that reflects exposure from current exogenous sources and the release of lead from bone. ${ }^{61}$

The US CDC has, for screening purposes, defined a blood lead level of $10 \mu \mathrm{g} / \mathrm{dl}$ as the threshold level of concern, a value never intended as a definition of what is safe or 'normal'. ${ }^{55}$ The CDC recommends that state and local health departments develop appropriate screening strategies for their areas. In the USA, some states have adopted universal annual screening of preschool children 1-5 years old for blood lead, and others have targeted those at highest risk. ${ }^{7}$ In many cases, the costs of universal screening exceeded the cost of health benefits. ${ }^{62}$ The recommendations for Medicaid-eligible children are mandated by those with authority over Medicaid. CDC guidelines are in agreement with this. All Medicaid-eligible children and children living in highrisk communities (e.g., those in which $12 \%$ or more of the children have blood lead levels $\geqslant 10 \mu \mathrm{g} / \mathrm{dl}$ ) are screened. Venesection is traumatic to many children and the balance of benefit and harm is a fine one, particularly where unselective, indiscriminate testing occurs.

Fetal risk from maternal exposure to lead during pregnancy is substantial, so women engaged in occupations or crafts known to have a risk of lead contamination should be screened periodically. Blood levels of concern for pregnant females are $5 \mu \mathrm{g} / \mathrm{dl}$ or higher. ${ }^{61}$ Gardella $^{63}$ showed a strong positive correlation between maternal and umbilical cord blood lead levels exceeding $10 \mu \mathrm{g} / \mathrm{dl}$. This is important in testing exposure to lead in utero.

The lead content of the surface enamel of deciduous teeth in children can be estimated by atomic absorption photometry. ${ }^{59}$ Lead accumulated in this part of the tooth is linked to the environment in which people reside and as such it can be used as a biomarker of lead exposure. ${ }^{64,65}$ It is unsuitable as a measure of acute recent exposures.

The use of zinc protoporphyrins (ZPP) can be helpful in individuals with moderate-to-high blood lead concentrations, where the objective is to determine the chronicity of exposure.,66 An elevated ZPP indicates circulating lead in the preceding 90 days. An elevated ZPP in a child shown to be iron-sufficient indicates a longer duration of exposure to lead, with a body burden (i.e., more lead deposition in bone) that will require more extensive chelation therapy. ${ }^{7}$ In cases where the timing and location of exposure is known, it carries little value. Potentially, it can also be used as a screening tool as a surrogate marker for blood lead. ${ }^{7,66}$ But the best screening tool and marker of lead exposure in children remains blood lead and should not be replaced by ZPP. ZPP measurements are fraught with difficulty because there is a poor correlation between ZPP and blood lead at lower blood lead concentrations. ${ }^{66}$ Moreover, there are other conditions (e.g., iron deficiency) that can increase ZPP and there is significant inter-individual variation in values. Thus, in the case of lead-dust exposure in Esperance, its use was rejected because of expected relatively low sensitivity and specificity. ${ }^{67}$ There is better correlation between ZPP and blood lead at higher concentrations ( $>20$ and particularly $>40 \mu \mathrm{g} / \mathrm{dl}) .{ }^{67}$

Speciation of lead by isotoping is a newly developed research application of a technique that is very helpful in identifying the source of lead exposure. ${ }^{65,68}$ By comparing the isotopic profiles (isotope ratio) of lead among samples, it is possible to identify or exclude source(s) that contribute to cases of pediatric lead poisoning. In cases of environmental exposure, it can confirm the source of exposure and also help to identify individuals who have not been exposed by this point source.

An abdominal X-ray may reveal recently ingested lead paint chips, ${ }^{33}$ sinkers, or plaster-sources of exposure that require removal with polyethylene glycol to prevent further lead absorption. 7,69 Long bone X-rays can show 'lead lines' (which represent growth arrest), ${ }^{33}$ but do not alter the way a case of child poisoning should be managed. ${ }^{7,69}$ Routine screening of populations with iron deficiency for lead is also of very limited value because of the low detection rate. ${ }^{70}$

Other risk factors for lead poisoning include concurrent iron deficiency, and it is important that pale or anemiclooking children are screened for this. ${ }^{71}$ Both conditions cause anemia and produce a more severe form when combined. The explanation for this is that lead is somehow taken up by the iron transport system in the gut, which is up-regulated in iron-deficient states. ${ }^{72,73}$ It follows that treatment of iron deficiency limits uptake of lead and helps with hematopoeisis, ${ }^{74}$ and thus the prevention of iron deficiency may represent a public health intervention for reducing lead exposure in humans. ${ }^{75}$ However, iron supplementation has not been shown to benefit iron-replete children with pre-existing lead poisoning and may reduce lead excretion. ${ }^{59}$ 


\section{Current and future intervention strategies to mitigate risk from lead}

The US CDC and the World Health Organization define a blood lead level of $10 \mu \mathrm{g} / \mathrm{dl}$ as the threshold level of concern, at which point active management of exposure to lead should be initiated. ${ }^{7}$ In addition to strategies discussed above, other lead-reduction strategies include changes in industrial working practices and litigation. ${ }^{7,22}$ Childhood lead-prevention programmes should concentrate on home visits and lead source investigations. ${ }^{54,76}$ Five randomized trials examined the effectiveness of intervention strategies, professional house cleaning, vacuuming with HEPA air filters, provision of an individualized healthcare plan, and parental teaching on lead exposure prevention. ${ }^{76}$ Only repeated professional house cleaning reduced the blood lead concentration significantly. However, because of ethical constraints, in four trials, the control group also had information about lead poisoning prevention, which is a confounding factor to the effects of the study intervention alone. ${ }^{76}$ Individual lead exposure-reduction strategies such as hand washing and wet mopping of dust reduce the lead burden attributed to dust, and allow an individual to regain a sense of control. ${ }^{7,22}$ In explaining the measures taken to reduce lead risk in a population, it is important to give people control over their own risk.

There is a very limited role for chelation therapy, using meso-2,3-dimercatosuccinic acid (DMSA), in cases where levels of lead in the body are elevated as a result of environmental exposure. In a randomized, double-blind, placebo-controlled trial conducted between September 1994 and June 2003 in the USA, 1854 children from 12-33 months with referral blood lead levels between 20 and $44 \mu \mathrm{g} / \mathrm{dl}$ $(0.96-2.12 \mu \mathrm{mol} / \mathrm{l})$ received chelation therapy with DMSA. This lowered their average blood lead concentrations for approximately six months, but resulted in no benefit in cognitive, behavioral, or neuromotor end points. ${ }^{77}$ There was no relationship between falling blood lead levels and improved cognition in the group treated with active drug. ${ }^{77,78}$ Although DMSA lowers blood lead in moderately poisoned children, it has no beneficial effect on growth and may have adverse effects. ${ }^{79}$ Even with higher blood lead concentrations, the problem in essence arises from ongoing exposure situations where continuing lead mining operations, such as Broken Hill in New South Wales, Australia, result in bone deposition of lead. When this happens, the reservoir of lead in bone is in equilibrium with blood. DMSA removes lead from blood, but probably only $1 \%$ of the total body burden. ${ }^{80-82}$ Re-equilibration then takes place and blood levels rise again. This can happen particularly sharply if ongoing exposure takes place. ${ }^{80,81}$ Thus, repeated chelation therapy is required to remove the lead. ${ }^{80,81}$ This may cause mild and reversible elevation of liver enzymes. In one study, there were no reported differences in liver function tests between participants treated with DMSA and placebo groups. ${ }^{44}$ Prevention of exposure is thus unquestionably a much more effective intervention strategy than post-exposure chelation therapy. However, it takes enormous efforts to reduce the time required to make a home 'lead safe' $^{82}$

Prevention of lead exposure is key to averting risk, so engineering solutions, dust monitoring of industrial sites, and lowering environmental pollution all show promise in this regard. As the evidence accumulates that lead toxicity is significant at lower doses than recognized earlier, there will be more pressure to reduce exposure from known lead sources. In meeting these needs, emerging technologies will need to be developed further to give early warning of the potential for exposure to take place. One such early warning technology is lead-dust monitoring of the air around ports and smelter stacks.

\section{Conclusions}

Many countries in the world have a public health burden from lead. In many developed regions, there is complacency because leaded petrol has been phased out, yet certain subpopulations remain exposed to the toxic metal. In the developing world, lead exposure is ongoing and comes from multiple sources. None of us can afford to be ignorant of the risks associated with lead. We need to know how to approach the issue of preventing exposure where possible, and how to apply appropriate health screening and surveillance approaches if exposure has occurred. Measuring blood lead concentrations remains the cornerstone of testing for degree of lead poisoning. Dealing with the population's fear of unemployment versus a fear of risks to children and tolerance of environmental toxins is a key issue in the modern world. Nowhere is there a better example of that than in cases of lead exposure. Toxicologists have a duty of care to present risks in a balanced way to allow communities to take informed decisions about prevention of exposure, and to recognize the likely health consequences of exposure to lead. People quite rightly expect their clinicians to be better informed and demonstrate excellence in risk communication.

\section{Conflicts of interest}

The author has no competing interests.

Provenance and peer review

Commissioned without payment; externally peer-reviewed.

\section{References}

1 Landrigan PJ, Schecter CB, Lipton JM, Fahs MC, Schwartz J. Environmental pollutants and disease in American children: estimates of morbidity, mortality, and costs for lead poisoning, asthma, cancer and developmental disabilities. Environ Health Perspect 2002;110:721-8.

2 Lanphear BP, Hornung R, Khoury J, Yolton K, Baghurst P, Bellinger DC, et al. Low-level environmental lead exposure and 
children's intellectual function: an international pooled analysis. Environ Health Perspect 2005;113:894-9.

3 Ris MD, Dietrich KN, Succop PA, Berger OG, Bornschein RL. Early exposure to lead and neuropsychological outcome in adolescence. I Int Neuropsychol Soc 2004;10:261-70.

4 Canfield RL, Henderson CR, Cory-Slechta DA, Cox C, Jusko TA, Lanphear BP. Intellectual impairment in children with blood lead concentrations below $10 \mu$ per deciliter. N Engl J Med 2003;16: 1517-26.

5 Lanphear BP, Dietrich K, Auinger P, Cox C. Cognitive deficits associated with blood lead concentrations $<10$ microg/dL in US children and adolescents. Public Health Rep 2000;115:521-9.

6 Lanphear BP, Hornung R, Ho M, Howard CR, Eberle S, Knauf K. Environmental lead exposure during childhood. I Paediatr 2002;140:40-7.

7 Woolf AD, Goldman R, Bellinger DC. Update on the clinical management of childhood lead poisoning. Pediatr Clin $\mathrm{N} \mathrm{Am}$ 2007;54:271-94.

8 Chung EK, Webb D, Clampet-Lunquist S, Campbell C. A comparison of elevated blood lead levels in children living in foster care, their siblings, and the general population. Pediatrics 2001;107:E81.

9 Falk $\mathrm{H}$. International environmental health for the paediatrician: case study of lead poisoning. Pediatrics 2003;112:259-64.

10 Fewtrell LJ, Pruss-Ustun A, Landrigan P, Ayuso-Mateos JL. Estimating the global burden of retardation and cardiovascular diseases from environmental lead exposure. Environ Res 2004;94: 120-33.

11 Education and Health Standing Committee. Esperance Port.com. $\mathrm{au}$ /issue.asp. Response of Western Australian Government to the Western Australian Legislative Assembly Education and Health Standing Committee in Relation to the Cause and Extent of lead Pollution in the Esperance Area. Available at: http://www. esperanceport.com.au/issue.asp. Retrieved November 28, 2007.

12 Pocock SJ, Smith M, Baghurst PA. Environmental lead and children's intelligence: a systematic review of the epidemiological evidence. Br Med J 1994;309:1189-97.

13 Baghurst PA, McMichael AJ, Wigg NR, Vimplani GV, Robertson $\mathrm{EF}$, Roberts RJ, et al. Environmental exposure to lead and children's intelligence at the age of seven years. The Port Pirie Cohort Study. N Engl J Med 1992;327:1308-9.

14 Government of Western Australia, Department of Health Website. http://www.health.wa.gov.au/home/.

15 Covello V, Allen F. Seven Cardinal Rules of Risk Communication. US Environmental Protection Agency, Office of Policy Analysis: Washington, DC, 1988.

16 Covello V, Sandman P. Risk communication: evolution and revolution. In: Wolbarst A (ed). Solutions to an Environment in Peril. John Hopkins University Press: Baltimore, USA, 2001. pp 164-78.

17 Reckelhoff-Dangel C, Petersen D. Risk Communication in Action: The Risk Communication Workbook. United States Environmental Protection Agency, Office of Research and Development: Cincinnati, OH, 2007.

18 Reynolds MA. Crisis and emergency risk communication. CDC, October 2002.

19 Corporation NS. Schedule B (8)-Guideline on Community Consultation and Risk Communication: Environmental Protection and Heritage Council, 2002.

20 Brown LM, Kim D, Yomai A, Meyer PA, Noonan GP, Huff D, et al. Blood lead levels and risk factors for lead poisoning in children and caregivers in Chuuk State, Micronesia. Int J Hyg Environ Health 2005;208:231-6.

21 Maas RP, Patch SC, Morgan DM, Pandolfo TJ. Reducing lead exposure from drinking water: recent history and current status. Public Health Reports 2005;120:316-21.

22 American Academy of Pediatrics-Policy Statement. Lead exposure in children: prevention, detection and management. Pediatrics 2005;116:1036-46.
23 Counter SA, Buchanan LH, Ortega F. Lead concentrations in maternal blood and breast milk and pediatric blood of Andean villagers: 2006 follow-up investigation. J Occup Environ Med 2007;49:302-9.

24 Bridbord K. Occupational lead exposure and women. Prev Med 1978;7:311-21.

25 Dorea JG. Mercury and lead during breast-feeding. Br J Nutr 2004;92:21-40.

26 Ettinger AS, Téllez-Rojo MM, Amarasiriwardena C, Bellinger D, Peterson K, Schwartz J, et al. Effect of breast milk lead on infant blood lead levels at 1 month of age. Environ Health Perspect 2004;112:1381-5.

27 Ettinger AS, Téllez-Rojo MM, Amarasiriwardena C, Peterson KE, Schwartz S, Aro A, et al. Influence of maternal bone lead burden and calcium intake on levels of lead in breast milk over the course of lactation. Am J Epidemiol 2006;163:48-56. Epub November 9, 2005.

28 US Environmental Protection Agency. Prohibition on gasoline containing lead or lead additives for highway use. Final rule 61. Federal register 1996; 3832-3838.

29 Australian Institute of Health and Welfare Report. Lead in Australian children: summary of the national survey of lead in children. Australian Institute of Health and Welfare 1996.

30 Centers for Disease Control and Prevention. Blood lead levelsUnited States, 1999-2002. MMWR Morb Mortal Weekly Rep 2005;54:513-16.

31 Stromberg U, Lundh T, Schutz A, Skerfving S. Yearly measurements of blood lead in Swedish children since 1978; an update focusing on the petrol lead free period 1995-2001. Occup Environ Med 2003;60:370-2.

32 Gordon JN, Taylor A, Bennett PN. Lead poisoning: case studies. Br I Clin Pharmacol 2002;53:451-8.

33 Marcus S. Lead toxicity. Available at: http://www.emedicine.com/ EMERG/topic293.htm.

34 Centers for Disease Control and Prevention. Update: blood lead levels-United States, 1991-1994. JAMA 1997;277:1031-2.

35 Mowad E, Haddad I, Gemmel DJ. Management of lead poisoning from ingested fishing sinkers. Arch Pediatr Adolesc Med 1998;152:485-8.

36 Dargan PI, Evans PH, House IM, Jones AL. A case of lead poisoning due to snooker chalk. Arch Dis Child 2000;83:519-20.

37 Schmidt CW. Face to face with toy safety-understanding an unexpected threat. Environ Health Perspect 2008;116:71-6.

38 Centers for Disease Control and Prevention. Death of a child after ingestion of a metallic charm-Minnesota 2006. MMWR Morb Mortal Weekly Rep 2006;55:340-1.

39 Saper RB, Kales SN, Paquin J, Burns MJ, Eisenberg DM, Davis RB, et al. Heavy metal content of Ayurvedic herbal medicine products. JAMA 2004;292:2868-72.

40 Marchetti C. Molecular targets of lead in brain neurotoxicity. Neurotox Res 2003;5:221-36

41 Toscano CD, Guilarte TR. Lead neurotoxicity: from exposure to molecular effects. Brain Res Rev 2005;49:529-54.

42 Kelada SN, Shelton E, Kaufmann RB, Khoury MJ. Aminolevulinic acid dehydratase genotype and lead toxicity: a HuGE review. Am J Epidemiol 2001;154:1-13.

43 Chen A, Cai B, Dietrich KN, Radcliff J, Rogan WJ. Lead exposure, IQ, and behaviour in urban 5-to 7-year olds: does lead affect behaviour only by lowering IQ? Pediatrics 2007;119:e650-8.

44 Chen A, Dietrich KM, Ware JH, Radcliff J, Rogan WJ. IQ and blood lead from 2 to 7 years of age: are the effects in older children the residual of high blood lead concentrations in 2-yearolds? Environ Health Perspect 2005;113:597-601.

45 Chen A, Schwarz D, Radcliffe J, Rogan WJ. Maternal IQ, child IQ, behaviour and achievement in olds. Pediatr Res 2006;59:471-7.

46 Schwartz J. Low-level lead exposure and children's IQ: a meta-analysis and search for a threshold. Environ Res 1994;65:42-55. 
47 Cecil KM, Brubaker CJ, Adler CM, Dietrich KN, Altaye M, Egelhof $\mathrm{JC}$, et al. Decreased brain volume in adults with childhood lead exposure. PLoS Med 2008;5:e112.

48 Selevan SG, Rice DC, Hogan KA, Euling SY, Pfahles-Hutchens A, Bethel J. Blood lead concentration and delayed puberty in girls. N Engl J Med 2003;348:1527-36.

49 Ekong EB, Jaar BG, Weaver VM. Lead-related nephrotoxicity: a review of the epidemiologic evidence. Kidney Int 2006;70: 2074-84. doi:10.1038/sj.ki.5001809; published online October $25,2006$.

50 Inglis JA, Henderson DA, Emmerson BT. The pathology and pathogenesis of chronic lead nephropathy occurring in Queensland. J Pathol 1978;124:65-76.

51 Bernard SM. Should the centers for disease control and prevention's childhood lead poisoning intervention level be lowered? Am J Public Health, Public Health Matters 2003;93:1253-60.

52 Centers for Disease Control and Prevention. 2005.

53 Rothenberg SJ, Rothenberg JC. Testing the dose-response specification in epidemiology: public health and policy consequences for lead. Environ Health Perspect 2005;113:1190-5.

54 Gilbert SG, Weiss B. A rationale for lowering the blood lead action level from 10 to $2 \mu \mathrm{g} / \mathrm{dl}$. Neurotoxicology 2006;27:693-701.

55 Centers for Disease Control and Prevention (CDC). Advisory committee on childhood lead poisoning prevention. MMWR Recomm Rep 2007;56 (RR-8): 1-16.

56 Schnaas L, Rothenberg SJ, Flores MF, Martinez S, Hernandez C, Osorio E. Reduced intellectual development in children with prenatal lead exposure. Environ Health Perspect 2006;114: 791-7.

57 Zentner LEA, Rondo HC, Mastroeni SSBS. Lead contamination and anthropometry of the newborn baby. J Trop Pediatr 2006;52: 369-71.

58 Manton WI, Angle CR, Stanek KL, Reese YR, Kuehnemann TJ. Acquisition and retention of lead by young children. Environ Res 2000;82:60-80.

59 Almeida GR, Pereira S, Barbosa Jr F, Krug FJ, Cury JA, Sousa M, et al. Lead contents in the surface enamel of deciduous teeth sampled in vivo from children in uncontaminated and in leadcontaminated areas. Environ Res 2007;104:337-45.

60 Roberts JR, Reigart JR, Ebeling M, Hulsey TC. Time required for blood lead levels to decline in nonchelated children. J Toxicol Clin Toxicol 2001;39:153-60.

$61 \mathrm{Hu} \mathrm{H}$, Rabinowitz M, Smith D. Bone lead as a biological marker in epidemiological studies of chronic toxicity: conceptual paradigms. Environ Health Perspect 1998;106:108.

62 Briss PA, Matte TD, Schwartz J, Rosenblum LS, Binder S. Costs and benefits of a universal screening program for elevated blood lead levels in 1 year-old children. In: Screening Young Children for Lead Poisoning: Guidance for State and Local Public Health Officials. CDC: Atlanta, Georgia, 1997. Appendix B4.

63 Gardella C. Lead exposure in pregnancy: a review of the literature and argument for routine prenatal screening. Obstet Gynaecol Surv 2001;56:231-8.

64 Karahalil B, Aykanat B, Erta ${ }^{\circ}$ N. Dental lead levels in children from two different urban and suburban areas of Turkey. Int J Hyg Environ Health 2007;210:107-12 Epub November 3, 2006.

65 Gwiazda R, Campbell C, Smith D. A noninvasive isotopic approach to estimate the bone lead contribution to blood in children: implications for assessing the efficacy of lead abatement. Environ Health Perspect 2005;113:104-10.

66 Milman N, Christensen JM, Ibsen KK. Blood lead and erythrocyte zinc protoporphyrin in mothers and newborn infants. Eur J Pediatr 1988:147:71-3.

67 Hammond PB, Bornschein RL, Succop P. Dose-effect and dose-response relationships of blood lead to erythrocytic protoporphyrin in young children. Environ Res 1985;38:187-96.

68 Naeher LP, Rubin CS, Hernandez-Avila M, Noonan GP, Paschal D, Narciso $\mathrm{J}$, et al. Use of isotope ratios to identify sources contributing to pediatric lead poisoning in Peru. Environ Health Perspect 2003;58:579-89.

69 Jones AL, Dargan PI. Churchill's Textbook of Toxicology. Churchill Livingstone: Edinburgh, Scotland, 2001. ISBN 0-443-06476-8.

70 Gawarammana IB, Dargan PI, Woodcock S, Sculley M, House IM, Wood DM, et al. Should all patients with unexplained anaemia be screened for chronic lead poisoning? Hum Exp Toxicol 2006;25:645-9.

71 Clarke M, Royal J, Seeler R. Interaction of iron deficiency and lead and the haematologic findings in children with severe lead poisoning. Pediatrics 1988;81:247-54.

72 Kwong WT, Friello P, Semba RD. Interactions between iron deficiency and lead poisoning: epidemiology and pathogenesis. Sci Total Environ 2004;330:21-37.

73 Heath LM, Soole KL, McLaughlin ML, McEwan GTA, Edwards JW. Toxicity of environmental lead and the influence of intestinal absorption in children. Rev Environ Health 2003; 18:231-50.

74 Hammada TA, Sexton M, Langenberg P. Relationship between blood lead and dietary iron intake in preschool children. A crosssectional study. Ann Epidemiol 1996;6:30-3.

75 Centers for Disease Control and Prevention. Managing Elevated Blood Lead Levels Among Young Children: Recommendations from the Advisory Committee of Childhood Lead Poisoning Prevention. Centers for Disease Control: Atlanta, 2002a.

76 Whitehead NS. Case management protocol and declining blood lead concentration among children. Prev Chronic Dis 2007;4:A05

77 Dietrich KN, Ware JH, Salganik M, Radcliff J, Rogan WJ, Rhoads $\mathrm{GC}$, et al. Effect of chelation therapy on the neuropsychological and behavioral development of lead-exposed children after school entry. Pediatrics 2004;114:19-26.

78 Rogan WJ, Dietrich KN, Ware JH, Dockery DW, Salganik M, Radcliffe J, et al. The effect of chelation therapy with succimer on neuropsychological development in children exposed to lead. $N$ Engl J Med 2001;44:1421-6.

79 Peterson KE, Salganik M, Campbell C, Rhoads GG, Rubin J, Berger $\mathrm{O}$, et al. Effect of succimer on growth of preschool children with moderate blood lead levels. Environ Health Perspect 2004;112: 233-7.

80 Chisolm Jr JJ. Safety and efficacy of meso-2, 2-dimercaptosuccinic acid (DMSA) in children with elevated blood lead concentrations. J Toxicol Clin Toxicol 2000;38:365-75.

81 Flanagan R, Jones AL. Antidotes. A Reference Manual. TaylorFrancis: London, 2001.

82 Zierold KM, Havlena J, Anderson H. Exposure to lead and length of time needed to make homes lead-safe for young children. Am J Public Health 2007;97:267-70.

83 Rabin R. Warnings unheeded: a history of child lead poisoning. Am J Public Health 1989;79:1668-74.

84 Shen X, Rosen JF, Guo D, Wu S. Childhood lead poisoning in China. Sci Total Environ 1996;181:101-9.

85 Jones TF, Moore WL, Craig AS, Reasons RL, Schaffner W. Hidden threats: lead poisoning from unusual sources. Pediatrics 1999; 104:1223-5.

86 Hernberg S. Lead poisoning in a historical perspective. Am J Ind Med 2000;38:244-54.

87 Lanphear BP, Weitzman M, Winter NL, Eberly S, Yakir B, Tanne $\mathrm{M}$, et al. Lead-contaminated house dust and urban children's blood lead levels. Am J Public Health 1996;86:1416-21.

88 Madhavan S, Rosenman KD, Shehata T. Lead in soil: recommended maximum permissible levels. Environ Res 1989;49: 136-42.

89 Dargan PI, Evans PH, House IM, Jones AL. A case of lead poisoning due to snooker chalk. Arch Dis Child 2000;83: 519-20.

90 Reissman DB, Matte TD, Gurnitz KL, Kaufmann RB, Leighton J. Is home renovation or repair a risk factor for exposure to lead 
among children residing in New York City? J Urban Health 2002;79:502-11.

91 Sonmez F, Donmez O, Sonmez HM, Keskinoglu A, Kabasakal C, Mir S. Lead exposure and urinary $N$-acetyl â Dglucosaminidase activity in adolescent workers in auto repair workshops. J Adolesc Health 2002;30:213-16.

92 Rabito FA, Iqbal S, Shorter CF, Osman P, Philips PE, Langlois E, et al. The association between demolition activity and children's blood lead levels. Environ Res 2007;103:345-51.

93 Sokas RK, Simmens S, Sophar K, Welch LS, Liziewski T. Lead levels in Maryland construction workers. Am J Ind Med 1997;31:188-94.
94 Zietz B, de Vergara JD, Kevekordes S, Dunkelberg H. Lead contamination in tap water of households with children in Lower Saxony, Germany. Sci Total Environ 2001;275:19-26.

95 Staudinger KC, Roth VS. Occupational lead poisoning. Am Fam Physician 1998;15:57.

96 Yang T, Tung HJ, Shyr JC, Lai CH, Loh CH, Liou SH. Ten-year follow-up of blood lead levels with medical removal protection of shipyard workers. Ind Health 2005;43:611-14.

97 Vork KL, Hammond K, Sparer J, Cullen MR. Prevention of lead poisoning in construction workers: a new public health approach. Am J Ind Med 2001;39:243-53. 